\title{
Stretching cells with DEAs
}

\author{
S. Akbari*a, S. Rosset ${ }^{\mathrm{a}}$, H. R. Shea ${ }^{\mathrm{a}}$ \\ ${ }^{a}$ Microsystems for Space Technologies Laboratory, École Polytechnique Fédérale de Lausanne (EPFL), Rue Jaquet Droz \\ 1, case postal 526, 2002, Neuchâtel, Switzerland
}

\begin{abstract}
Biological cells regulate their biochemical behavior in response to mechanical stress present in their organism. Most of the available cell cultures designed to study the effect of mechanical stimuli on cells are $\mathrm{cm}^{2}$ area, far too large to monitor single cell response or have a very low throughput. We have developed two sets of high throughput single cell stretcher devices based on dielectric elastomer microactuators to stretch groups of individual cells with various strain levels in a single experiment. The first device consists of an array of $100 \mu \mathrm{m} \times 200 \mu \mathrm{m}$ actuators on a non-stretched PDMS membrane bonded to a Pyrex chip, showing up to $4.7 \%$ strain at the electric field of $96 \mathrm{~V} / \mu \mathrm{m}$. The second device contains an array of $100 \mu \mathrm{m} \times 100 \mu \mathrm{m}$ actuators on a $160 \%$ uniaxially prestretched PDMS membrane suspended over a frame. $37 \%$ strain is recorded at the nominal electric field of $114 \mathrm{~V} / \mu \mathrm{m}$. The performance of these devices as a cell stretcher is assessed by comparing their static and dynamic behavior.
\end{abstract}

Keywords: cell stretching, mechanotransduction, dielectric elastomer actuator, low-energy ion-implantation, microactuator.

\section{INTRODUCTION}

Biological cells proliferate, differentiate, migrate, or express genes in response to mechanical stress present in their organism [1-3]. This mechanical stress can originate from several sources such as: gravity, compression forces within joints, and dynamic mechanical stimulation resulting from muscular activity, which is often periodic such as heartbeat and breathing. Moreover, many forms of cell behavior such as migration, axonal outgrowth, blood clotting and extracellular matrix deposition are also regulated by mechanical stimuli [4-6]. Indeed, most cells utilize some form of mechanotransduction for their survival.

Investigation of the cell mechanotransduction mechanisms is currently performed with simple membrane cell-stretching equipment with limited capabilities, relying on the distension of a flexible membrane by a vacuum (e.g those made by Flexcell International corp.[7]), or mechanical motor, with loss of fidelity of the mechanical signal, as reviewed by Brown [8]. Uniaxial, biaxial, radial or circumferential strain can be applied, with strain of up to $20 \%$ at frequencies of order $1 \mathrm{~Hz}$. These devices have two major limitations; 1) The stretched areas are often in the range of centimeters, much too large to monitor single-cell responses. Therefore, the averaged response of hundreds of thousands of cells is monitored. 2) Despite having an array of stretching wells, one single strain level can be applied to all the cells, resulting in a low throughput. A few microelectromechanical systems on silicon substrate have been developed to apply uniaxial or biaxial strain to single cells $[9,10]$. They can apply reliable and calibrated strain levels, though at a very low throughput, meaning that they can stretch only one single cell in one experiment. On the other hand, to increase the throughput, arrays of mm size separately controllable cell stretching devices have been developed, which are still too large to monitor single cell responses [11-13].

*samin.akbari@epfl.ch; phone +41 32720 5460; fax +41 32 720 5754; http://lmts.epfl.ch

Electroactive Polymer Actuators and Devices (EAPAD) 2012, edited by Yoseph Bar-Cohen,

Proc. of SPIE Vol. 8340, 83401R - (C) 2012 SPIE · CCC code: 0277-786X/12/\$18 - doi: 10.1117/12.915180

Proc. of SPIE Vol. $834083401 R-1$ 
Based on dielectric elastomer actuators (DEAs), we have developed cell stretching devices that are capable of stretching groups of individual cells, addressing the both limitation of current cell stretchers. Dielectric elastomer actuators are compliant devices capable of generating large percentage strain with sub-second response time [14, 15], ideally suited for cell stretching application. A DEA is basically a soft thin elastomer sandwiched between two compliant electrodes. When a voltage (of order of $1 \mathrm{kV}$ ) is applied between the electrodes, the elastomer is squeezed in thickness due to the electrostatic pressure and it expands in-plane as it is incompressible. In our cell stretching devices, the cells will be cultured on the actuators and stretched while the elastomer expands in-plane. The actuators are made of silicone based elastomers proven to be biocompatible [16], eliminating the need for further surface modification for cell compatibility. The Young's modulus of the elastomer is in the range of $500 \mathrm{kPa}$ to $2 \mathrm{MPa}$, much higher than the stiffness of cells $(0.2$ $40 \mathrm{kPa}$ depending on the cell type [17]). Therefore, mechanical interaction with cells will not significantly influence the actuators' performance. Furthermore, the actuation strain is controllable by the applied voltage, making it possible to have an array of cell stretchers with various strain levels at the same cell culture, eliminating the need for multiple experiments over several days.

To make array of micro DEAs ( $\mu \mathrm{DEA}$ ) with the same size order of single cells, it is required to pattern the compliant electrodes on the micro scale, which is challenging using traditional compliant electrodes. Consequently, only few miniature dielectric elastomer actuators have been reported [18-22]. To pattern the micro scale compliant electrodes, we use low-energy ion-implantation to implant gold ions into the PDMS membrane at energies lower than $5 \mathrm{keV}$ using a filtered cathodic vacuum arc source. This leads to nanometer size gold clusters in the top $50 \mathrm{~nm}$ of the PDMS surface that create a conductive path sustaining up to $175 \%$ uniaxial stretch $[23,24]$. Increasing the gold dose increases the conductivity, but also increases the stiffness of the gold-PDMS composite. Just above the percolation threshold, the conductivity is good enough for the dielectric elastomer actuators $(1 \mathrm{k} \Omega / \mathrm{square})$ and the Young's modulus of the gold implanted PDMS is increased by only about $40 \%$ compared to non-implanted PDMS. Our group has shown that ionimplantation is an effective technique for making mm-scale EAPs, for instance buckling mode actuators [25], tunable lenses [26] or tunable acoustic filters [27].

Using low-energy ion-implantation, we have patterned $100 \mu \mathrm{m}$ wide compliant electrodes and fabricated two arrays of dielectric elastomer microactuators to stretch groups of individual cells, which are described in sections 2 and 3 . The first device consists of an array of $100 \mu \mathrm{m} \times 200 \mu \mathrm{m}$ actuators on a non-stretched $30 \mu \mathrm{m}$ thick PDMS membrane bonded on a Pyrex chip [28, 29]. Up to $4.7 \%$ uni-axial strain is recorded at the electric field of $96 \mathrm{~V} / \mu \mathrm{m}$. The actuation stress is quadratically related to the applied voltage and is limited by buckling mode of the nonstretched membrane or electrical break down voltage of PDMS membrane. The second device contains an array of $100 \mu \mathrm{m}$ x $100 \mu \mathrm{m}$ actuators on a $160 \%$ uniaxially prestretched PDMS membrane suspended over a frame [30,31]. Two perpendicular arrays of $100 \mu \mathrm{m}$ wide electrodes are patterned on top and bottom layer of the membrane. When a voltage is applied, at the intersection of the electrodes, membrane expands uniaxially due to anisotropic stiffening of the membrane. $37 \%$ strain is recorded at the nominal electric field of $114 \mathrm{~V} / \mu \mathrm{m}$. The design principle, fabrication process, and characterization of the abovementioned microEAPs are discussed in this paper and their performance as a cell stretcher is assessed.

\section{BONDED NON-STRETCHED $\mu$ DEA}

\subsection{Design principle}

The device consists of a $30 \mu \mathrm{m}$ thick non-stretched PDMS membrane with an array of $100 \mu \mathrm{m}$ wide electrodes on one side and a blanket electrode on the other side as schematically shown in Figure 1. In order to have uni-axial in-plane strain, the y-axis displacement is confined by bonding the membrane to a Pyrex chip with $200 \mu \mathrm{m}$ wide channels. In this case, the actuator is at the intersection of the $100 \mu \mathrm{m}$ wide electrodes where the electrostatic force locally compresses the membrane in thickness and the $200 \mu \mathrm{m}$ channels over which the membrane is free to expand in-plain.

Once the chip is fabricated, a single cell will be attached on each actuator and stretched uniaxially when the membrane expands over the trench. This is feasible by either patterning cell adherent extracellular-matrix protein on the actuator or 
patterning protein repellent co-polymers such as poly-1-lysine grafted polyethylene glycol (PLL-g-PEG) on the surface except on the actuator by micro-contact printing $[32,33]$. In order to avoid applying high electric field to the cells, the high voltage is applied to the bottom electrodes and the top surface where the cells will be cultured is grounded. The cells are immersed in conductive cell culture medium which is grounded with the top electrode, eliminating the electric field reaching the surface by fringe field through the air.

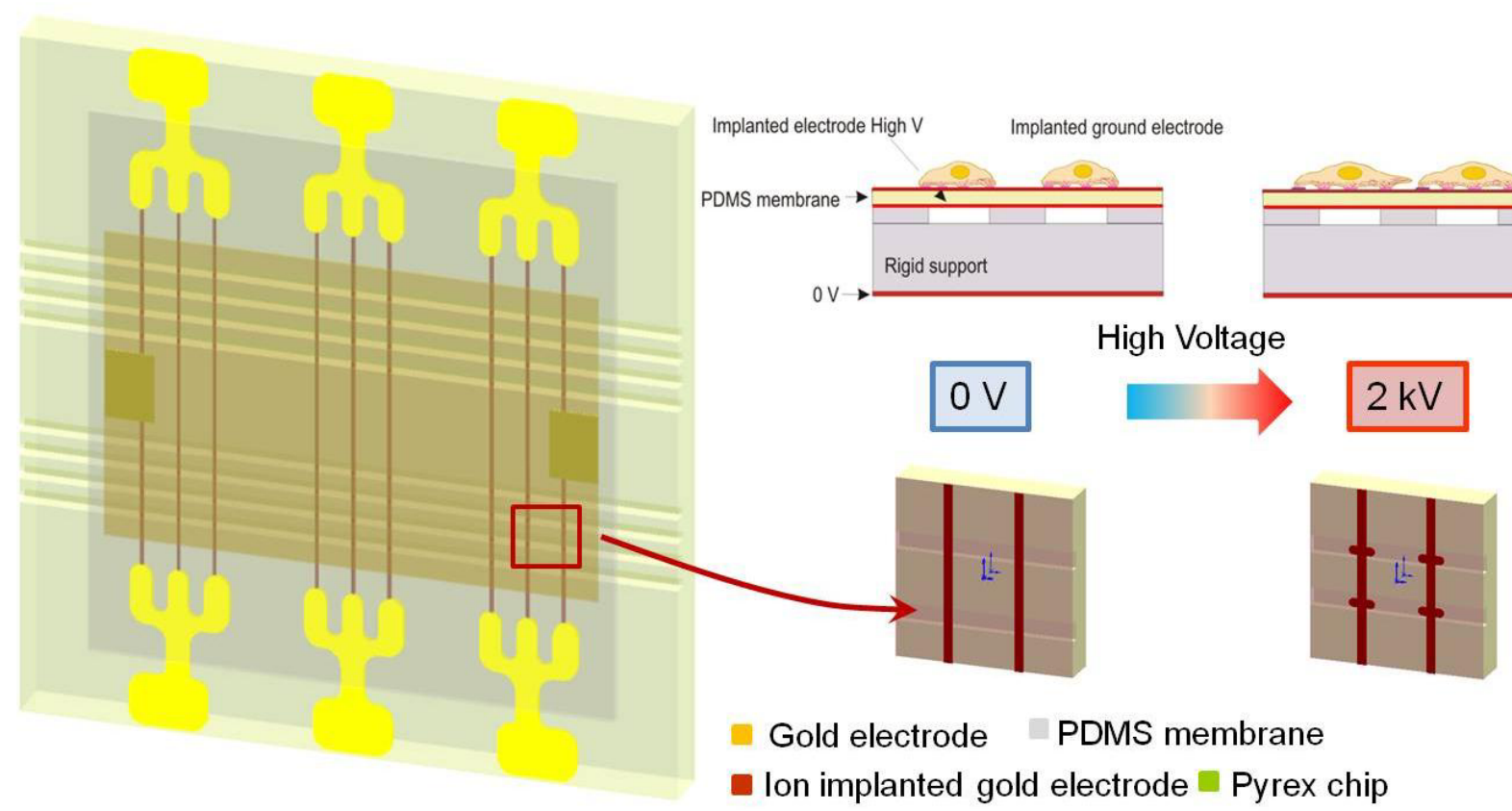

Figure 1. Left: Schematic of the array of microactuators consisting of a $30 \mu \mathrm{m}$ thick membrane bonded on a Pyrex chip with $200 \mu \mathrm{m}$ trenches. Red vertical lines represent the $100 \mu \mathrm{m}$ wide ion implanted gold electrodes on the bonded side of the membrane and there is

a blanket ion implanted electrode on top. The comb shape gold electrodes are patterned on the Pyrex chip to access the bottom electrodes and two small gold electrodes on top are patterned by sputtering to connect the wires to the top electrode. Right: Cross section view of two actuators with single cells adhered on each of them is shown on top and the isometric view of four actuators is shown on bottom, explaining that when a high voltage is applied, the actuators expand uniaxially over the trench and stretch the cells.

\subsection{Fabrication}

To fabricate an array of uni-axial cell stretchers, first, Pyrex chips with patterned gold electrodes and $200 \mu \mathrm{m}$ wide, 100 $\mu \mathrm{m}$ deep etched, channels are fabricated by powder blasting. Then, a $30 \mu \mathrm{m}$ thick PDMS membrane is cast and an array of $100 \mu \mathrm{m}$ wide parallel compliant electrodes is patterned with low-energy ion-implantation. Finally, the implanted side of the membrane is bonded to the Pyrex chip, and a blanket electrode is ion-implanted on the other side of the membrane. The fabrication process is shown in Figure 2. 


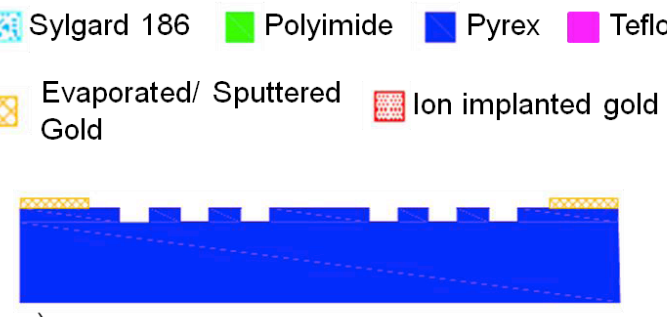

a)

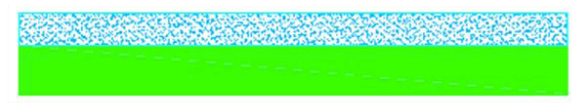

b)

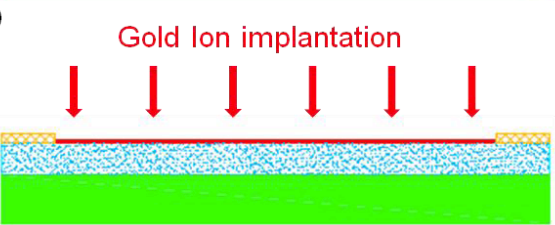

c)

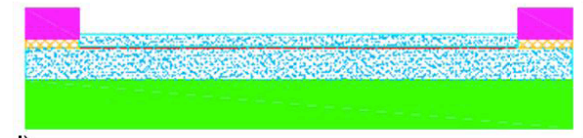

d)

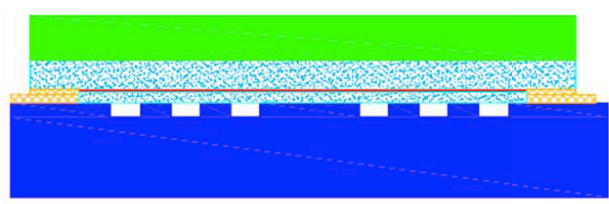

e)

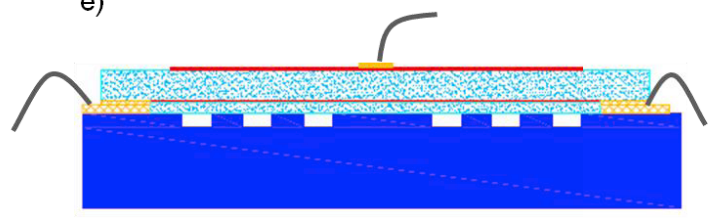

f)

Figure 2. a) Gold electrodes are patterned on a Pyrex substrate and $200 \mu \mathrm{m}$ wide $100 \mu \mathrm{m}$ deep channels are etched by powder blasting. b) $30 \mu \mathrm{m}$ PDMS membrane is casted over a support film (polyimide, Upilex-50S from UBE Industries, Ltd). c) The gold ions are selectively implanted through a shadow mask in our ion implanter at an energy of $-2.5 \mathrm{keV}$ and the gold contacts at the end of the wires are deposited. d) A thin layer of PDMS is casted over the main film and cured while the contact pads are covered. e) The PDMS

membrane is chemically bonded to the substrate. f) The top layer of the membrane is ion implanted and the gold contacts are deposited by sputtering.

Figure 3 shows the fabricated device consisting of three separate groups of EAP actuators that can be actuated with different voltages and frequencies, making it possible to stimulate different groups of cells with various strains in the same cell culture.

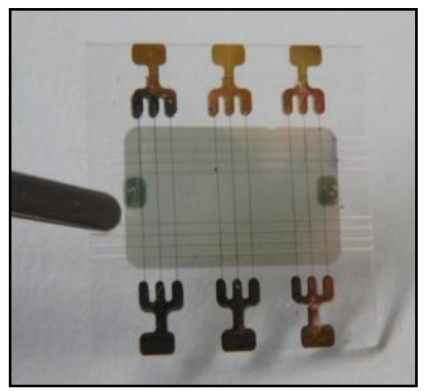

Figure 3. Fabricated bonded non-stretched device comprising $72100 \mu \mathrm{m}$ x $200 \mu \mathrm{m}$ dielectric elastomer actuators [29].

\subsection{Characterization}

Measuring the in-plane strain by optically detecting the expansion of the $100 \mu \mathrm{m}$ wide electrodes is not accurate for strains lower than $10 \%$. Therefore, we have deposited an array of $4 \mu \mathrm{m}$ diameter $100 \mathrm{~nm}$ thick aluminum dots on the actuators as shown in Figure 4b. Two images are recorded before and after applying the voltage and the position of the dots are detected and compared to calculate the displacement profile of the elastomer. The background mesh in Figure 4a represents the array of $\mathrm{Al}$ dots at zero voltage and the displacement profile of the dots after applying the voltage is mapped in contour on the mesh. As shown in Figure $4 \mathrm{~b}$ the array of dots is covering a larger area than the actuator in order to precisely study the actuators' performance. 

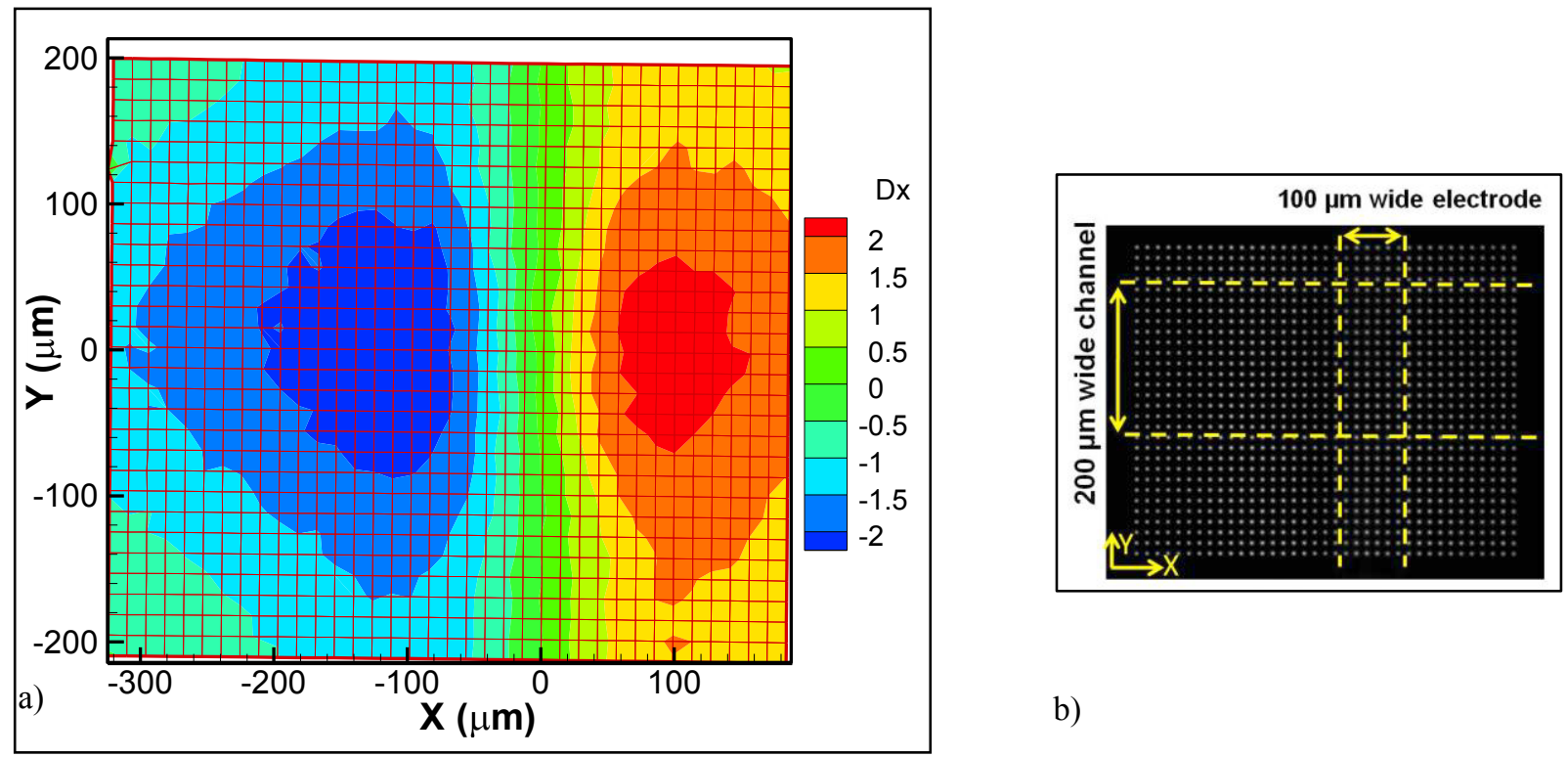

b)

Figure 4. - a) Deformation profile of an actuator, at $2.6 \mathrm{kV}$, derived by subtracting positions of dots before and after actuation; Center of the actuator is at $(0,0)$. The actuator is $100 \mu \mathrm{m} \times 200 \mu \mathrm{m}$ in a device with $30 \mu \mathrm{m}$ thick Sylgard 186 membrane. The intermediate PDMS layer used for bonding is $3 \mu \mathrm{m}$ thick (Sylgard 186, mixing ratio 1:20, (PDMS: Solvent, 1:2)). b) An actuator with $100 \mu \mathrm{m}$ wide electrode suspending over a $200 \mu \mathrm{m}$ channel covered with an array of $4 \mu \mathrm{m}$ aluminum dots.

To calculate the $\mathrm{x}$-axis strain, the smoothed $\mathrm{x}$-axis displacement along the $\mathrm{x}$-axis is differentiated. Figure 5 shows the maximum actuation strain along the channels on the Pyrex chip as the applied voltage is increased. The in-plane uniaxial strain is increased up to $4.7 \%$ at the electric field of $96 \mathrm{~V} / \mu \mathrm{m}$ and then the membrane is buckled out of plane and finally failed at the electric field of $105 \mathrm{~V} / \mu \mathrm{m}$ due to electrical break down of PDMS membrane.

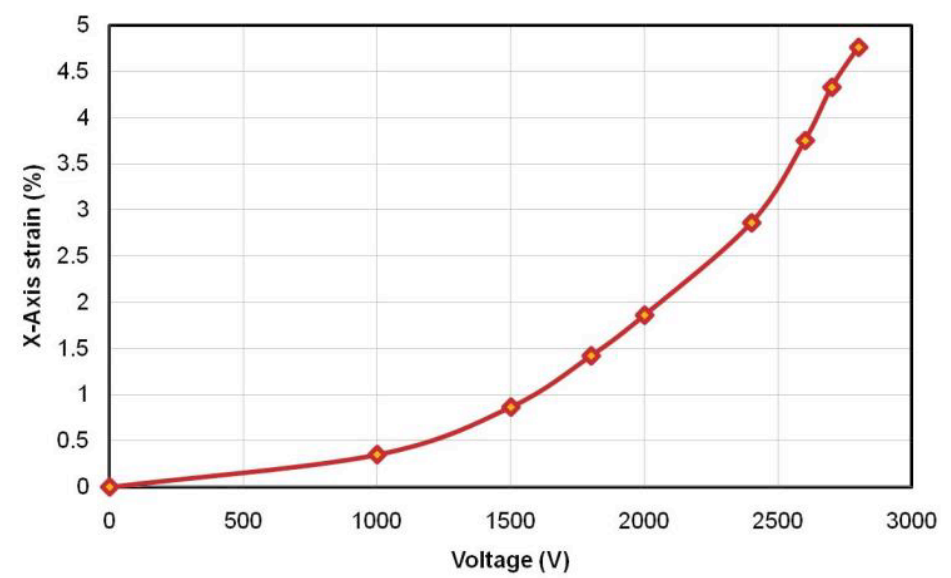

Figure 5. Measured $\mathrm{x}$-axis in-plane strain vs. drive voltage, showing the expected $\mathrm{V}^{2}$ scaling. A maximum in-plane strain of $4.7 \%$ is observed at $2.9 \mathrm{kV}[29]$.

Considering the actuation strain of up to $4.7 \%$, the bonded nonstretched $\mu$ DEA devices are mostly suitable to stretch the cells from stiffer tissues such as bone cells. Increasing the actuation strain to cover the required strain level for all cell type (up to 20\%) is feasible by using elastomers that are either softer or have a higher electrical break down strength. In the next section, we will explain that uniaxially prestretching the silicone elastomer is an effective technique to enhance the electrical break down and the actuation strain level. 


\section{SUSPENDED PRESTRETCHED $\mu$ DEA}

\subsection{Design principle}

In this device, the dielectric elastomer microactuators are fabricated on a highly uniaxially prestretched PDMS membrane (stretch ratio of up to $175 \%$ ). Two perpendicular compliant electrodes are patterned on top and bottom layer of the membrane as shown in Figure 6a. When a high voltage is applied between the electrodes, due to the Maxwell stress, at the intersection of the electrodes, the membrane is squeezed in thickness and expands in-plane. Due to anisotropic stiffening of the hyperlastic PDMS membrane by uniaxial prestretching, the maximum in-plane strain occurs in the nonstretched softer direction.

In order to avoid short circuiting the top ground electrode by the conductive cell growth medium, another nonstretched $30 \mu \mathrm{m}$ thick PDMS membrane is bonded on the actuators. The single cells are then attached on the actuators at the intersection of the electrodes (Figure $6 \mathrm{~b}$ ).
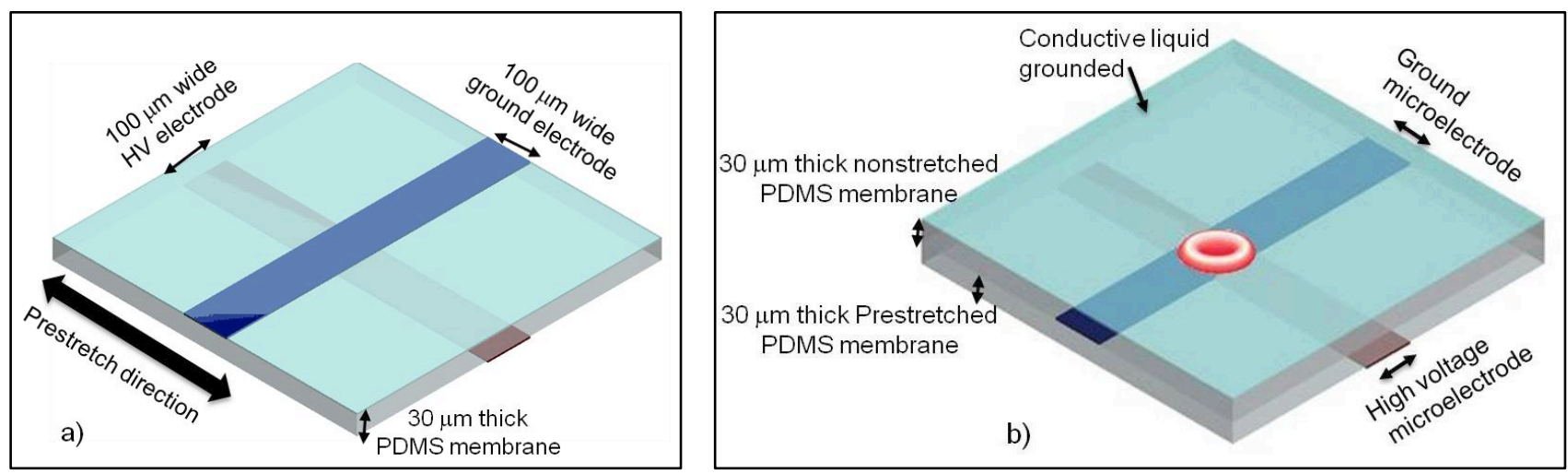

Figure 6. a) A single layer microactuator on a uniaxially prestretched $30 \mu \mathrm{m}$ thick PDMS membrane; Two perpendicular compliant microelectrodes are patterned on top and bottom layer of the membrane. The microactuator is at the intersection of the electrodes, where the electrostatic pressure exists. b) A nonstretched $30 \mu \mathrm{m}$ thick PDMS membrane is bonded on the single layer actuator to prevent short circuiting the top ground electrode by the conductive cell growth medium. A single cell is attached on the actuator at the intersection of the perpendicular electrodes.

\subsection{Fabrication}

First a $50 \mu \mathrm{m}$ thick PDMS membrane is prepared and stretched 2.7 times of its initial lenght in one direction and fixed on a frame. Then, two arrays of perpendicular electrodes are patterned on top and bottom layer of the membrane using lowenergy ion-implantation, with the same parameters than for the previous device. Next, the membrane is fixed between two PCBs and the electrical contact between the ion implanted electrode and the PCB is established by silver epoxy. Finally, another $30 \mu \mathrm{m}$ thick non-stretched PDMS membrane is bonded on the prestretched membrane and a cell culture dish is glued on top.

\subsection{Characterization}

To characterize the in-plane strains of the microactuators, microscope images are recorded for different actuation voltages. The widths of the electrodes before and after actuation are compared with the ImageJ software [34]. The displacement field is assumed to be linear and the relative strain is calculated by dividing the electrode's width increase to the initial width in the prestretched state. Figure $7 \mathrm{a}$, shows the actuation strain of a single layer $100 \mathrm{x} 100 \mu \mathrm{m}^{2}$ actuator made on a $175 \%$ uniaxially prestretched membrane. Up to $80 \%$ strain in the non pre-stretched direction is generated. After bonding a $20 \mu \mathrm{m}$ thick nonstretched PDMS membrane on top, the maximum actuation strain is reduced to $37 \%$ but still covering the required 1-20\% strain range to stimulate different cell types [35]. 

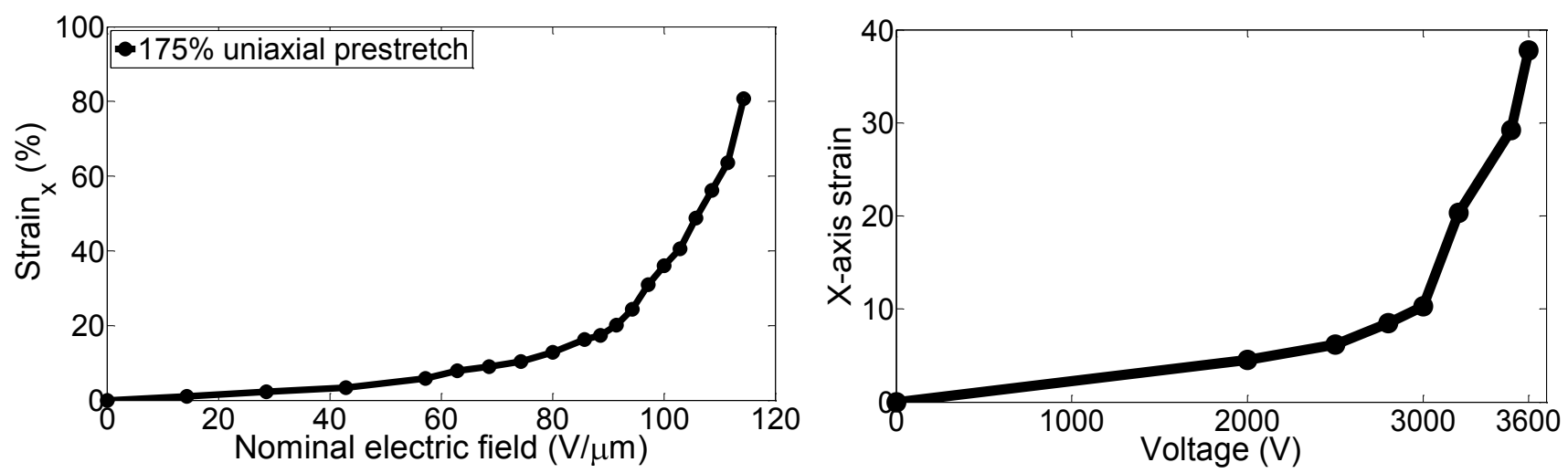

Figure 7. a) Actuation strain of a single layer actuator on a $175 \%$ uniaxially prestretched membrane. The strain along the nonstretched direction can be increased up to $80 \%$. b) The actuation strain of a double layer actuator compatible with cell stretching application is increased up to $37 \%$ [31].

\section{DISCUSSION}

Two sets of dielectric elastomer microactuators described above for cell stretching applications are shown in Figure 8. The cells can be cultured directly on the PDMS membrane and the holder in Figure 8a, and the cell culture dish in Figure $8 \mathrm{~b}$ isolate the high voltage electrodes from the conductive cell growth medium. The cell growth medium will also be grounded to ensure eliminating any electric field reaching the cells by fringe field through the air, as the cells are sensitive to electric fields of above $1 \mathrm{~V} / \mathrm{cm}[36]$.

The bonded nonstretched $\mu$ DEA device is more suitable for stretching cells of stiffer tissues such as bone cells as they already respond to $1 \%$ strain levels [37]. The actuation strain is limited by the low electrical break down electric field of nonstretched PDMS membrane. On the other hand, uniaxially prestretching the PDMS membrane has the advantage of retarding the pull-in instability and thus enhancing the sustainable break down electric field. Moreover, due to anisotropic stiffness of the membrane, the generated actuation strain in the nonstretched direction is higher than the case that the membrane is not prestretched. Therefore, much higher strain levels have been obtained with the suspended prestretched $\mu$ DEA device. This device is suitable for stretching all cell types. The sub-second response time of both devices makes it possible to stretch the cells with relevant biological frequencies [35].
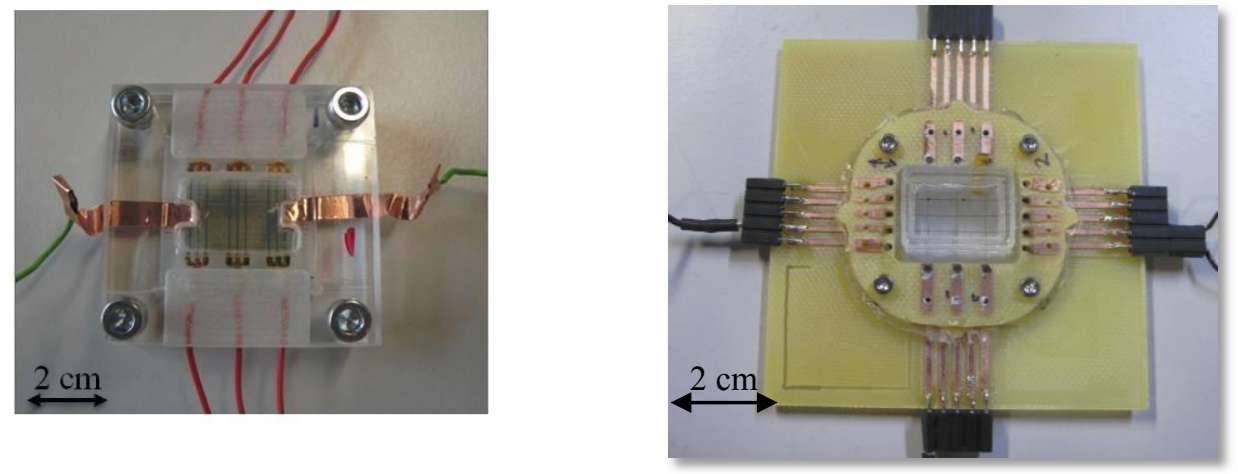

Figure 8. a) A bonded nonstretched $\mu$ DEA device comprising $72100 \mu \mathrm{m} \times 200 \mu \mathrm{m}$ actuators in its holder designed for ease of liquid handling. b) A suspended prestretched $\mu$ DEA device composed of $15100 \mu \mathrm{m} \times 100 \mu \mathrm{m}$ actuators fixed between two PCBs. The cell culture dish is placed on top of the actuators for biological experiments.

A possible weakness of dielectric elastomer actuators is reduced lifetime when operated in salt water compared to air, as elastomers such as PDMS are porous and can absorb the humidity resulting in short circuit through the membrane. The 
suspended prestretched $\mu$ DEA device presented here has survived continuous operation in salt water for two and a half days at $1 \mathrm{~Hz}$ frequency thanks to the passive PDMS membrane on the actuators.

\section{CONCLUSION}

Mechanical stress is ubiquitous in our body and cells modulate their developmental programs in response to it. In order to efficiently study the effect of mechanical stimulation on cells, we have developed a new technology based on dielectric elastomer actuators that addresses many of unmet demands of biologists such as high throughput and single cell stretching.

The operating principle, fabrication process and characterization of two sets of cell stretching devices were presented and their performance for cell stretching application was discussed. They consist of an array of microactuators that are grouped in subsections controlled by different voltages and frequencies, thus allowing various strain levels applied to multiple groups of cells in the same cell culture and in one experiment. The actuators are slightly larger than a single cell, capable of stretching an individual cell followed by patterning extracellular matrix on the actuators. The entire packaged devices are only a few $\mathrm{cm}^{2}$ in area that can easily fit in the incubator or directly on the oil immersion microscopes, easing the biological experiments and microscopy.

\section{ACKNOWLEGEMENTS}

We gratefully acknowledge financial support from the Swiss National Science Foundation grant \#200020-130453, thank Dr. A. Franco-Obregon from ETHZ-Space biology lab for helpful advice on cell mechanobiology, and Dr. O. VazquezMena from EPFL-LMIS1 for fabrication of the stencil masks.

\section{REFERENCES}

[1] C. H. Turner, and F. M. Pavalko, "Mechanotransduction and functional response of the skeleton to physical stress: The mechanisms and mechanics of bone adaptation," Journal of Orthopaedic Science, 3(6), 346-355 (1998).

[2] H. Troy A, "Mechanotransduction and the regulation of mTORC1 signaling in skeletal muscle," The International Journal of Biochemistry \& Cell Biology, 43(9), 1267-1276 (2011).

[3] D. J. Papachristou, K. K. Papachroni, E. K. Basdra et al., "Signaling networks and transcription factors regulating mechanotransduction in bone," BioEssays, 31(7), 794-804 (2009).

[4] A. J. Grodzinsky, M. E. Levenston, M. Jin et al., "Cartillage tissue remodeling in response to mechanical forces," Annual Review of Biomedical Engineering, 2(1), 691-713 (2000).

[5] G. K. Owens, "Role of mechanical strain in regulation of differentiation of vascular smooth muscle cells," Circulation research, 79(5), 1054-5 (1996).

[6] B. Eckes., and T. Krieg, "Regulation of connective tissue homeostasis in the skin by mechanical forces," Clin Exp Rheumatol, 22(3 Suppl 33), S73-76 (2004).

[7] "http://www.flexcellint.com/index.html."

[8] T. D. Brown, "Techniques for mechanical stimulation of cells in vitro: A review," Journal of Biomechanics, 33(1), 3-14 (2000).

[9] D. Desmaële, M. Boukallel, and S. Régnier, "Actuation means for the mechanical stimulation of living cells via microelectromechanical systems: A critical review," Journal of Biomechanics, 44(8), 1433-1446 (2011).

[10] D. B. Serrell, T. L. Oreskovic, A. J. Slifka et al., "A uniaxial bioMEMS device for quantitative forcedisplacement measurements," Biomedical Microdevices, 9(2), 267-275 (2007).

[11] C. Moraes, J.-H. Chen, Y. Sun et al., "Microfabricated arrays for high-throughput screening of cellular response to cyclic substrate deformation," Lab on a Chip, 10(2), 227-234 (2010).

[12] C. S. Simmons, J. Y. Sim, P. Baechtold et al., "Integrated strain array for cellular mechanobiology studies," Journal of Micromechanics and Microengineering, 21(5), 054016-10 (2011). 
[13] Y. Kamotani, T. Bersano-Begey, N. Kato et al., "Individually programmable cell stretching microwell arrays actuated by a Braille display," Biomaterials, 29(17), 2646-2655 (2008).

[14] P. Brochu, and Q. Pei, "Advances in Dielectric Elastomers for Actuators and Artificial Muscles," Macromolecular Rapid Communications, 31(1), 10-36 (2010).

[15] R. Pelrine, R. Kornbluh, Q. Pei et al., "High-speed electrically actuated elastomers with strain greater than 100\%," Science, 287(5454), 836-839 (2000).

[16] M. C. Bélanger, and Y. Marois, "Hemocompatibility, biocompatibility, inflammatory and in vivo studies of primary reference materials low-density polyethylene and polydimethylsiloxane: A review," Journal of Biomedical Materials Research, 58(5), 467-477 (2001).

[17] T. G. Kuznetsova, M. N. Starodubtseva, N. I. Yegorenkov et al., "Atomic force microscopy probing of cell elasticity," Micron, 38(8), 824-833 (2007).

[18] M. Aschwanden, and A. Stemmer, "Low voltage, highly tunable diffraction grating based on dielectric elastomer actuators," Proc. SPIE. 6524, 65241N1-10 (2007).

[19] P. Lotz, M. Matysek, and H. F. Schlaak, "Fabrication and Application of Miniaturized Dielectric Elastomer Stack Actuators," Transactions on Mechatronics IEEE/ASME 16(1), 58-66 (2011).

[20] X. Niu, P. Brochu, B. Salazar et al., "Refreshable tactile displays based on Bistable Electroactive Polymer," Proceeding of SPIE. 7976, $797610-5$ (2011).

[21] A. Pimpin, Y. Suzuki, and N. Kasagi, "Microelectrostrictive Actuator With Large Out-of-Plane Deformation for Flow-Control Application," Journal of Microelectromechanical Systems, 16(3), 753-764 (2007).

[22] H. Shea, "Miniaturized EAPs with compliant electrodes fabricated by ion implantation," Proceeding of SPIE. 7976, 79760R-1-9 (2011).

[23] M. Niklaus, and H. R. Shea, "Electrical conductivity and Young's modulus of flexible nanocomposites made by metal-ion implantation of polydimethylsiloxane: The relationship between nanostructure and macroscopic properties," Acta Materialia, 59(2), 830-840 (2011).

[24] S. Rosset, M. Niklaus, P. Dubois et al., "Metal Ion Implantation for the Fabrication of Stretchable Electrodes on Elastomers," Advanced Functional Materials, 19(3), 470-478 (2009).

[25] S. Rosset, M. Niklaus, P. Dubois et al., "Large-stroke dielectric elastomer actuators with ion-implanted electrodes," Journal of Microelectromechanical Systems, 18(6), 1300-1308 (2009).

[26] M. Niklaus, S. Rosset, P. Dubois et al., "Ion-implanted compliant electrodes used in dielectric electroactive polymer actuators with large displacement," Procedia Chemistry, 1(1), 702-705 (2009).

[27] P. Dubois, S. Rosset, M. Niklaus et al., "Voltage Control of the Resonance Frequency of Dielectric Electroactive Polymer (DEAP) Membranes," Journal of Microelectromechanical Systems 17(5), 1072-1081 (2008).

[28] S. Akbari, M. Niklaus, and H. Shea, "Arrays of EAP micro-actuators for single-cell stretching applications," Proceeding of SPIE. 7642, 76420H-1-10 (2010).

[29] S. Akbari, and H. Shea, "Microfabrication and characterization of an array of dielectric elastomer actuators generating uniaxial strain to stretch individual cells," Journal of Micromechanics and Microengineering, Accepted, (2012).

[30] S. Akbari, and H. Shea, "Arrays of $100 \mu \mathrm{m} \times 100 \mu \mathrm{m}$ dielectric elastomer actuators to strain the single cells," Procedia Engineering, 25(0), 693-696 (2011).

[31] S. Akbari, and H. Shea, "An array of $100 \mu \mathrm{m} \times 100 \mu \mathrm{m}$ Dielectric Elastomer Actuators with 80\% Strain for Tissue Engineering Applications," Sensors and Actuators A: Physical, In press, (2012).

[32] G. Csucs, R. Michel, J. W. Lussi et al., "Microcontact printing of novel co-polymers in combination with proteins for cell-biological applications," Biomaterials, 24(10), 1713-1720 (2003).

[33] L. Kam, and S. G. Boxer, "Cell adhesion to protein-micropatterned-supported lipid bilayer membranes," Journal of Biomedical Materials Research, 55(4), 487-495 (2001).

[34] [http://rsbweb.nih.gov/ij/].

[35] J. Wang, and B. Thampatty, "An Introductory Review of Cell Mechanobiology," Biomechanics and Modeling in Mechanobiology, 5(1), 1-16 (2006).

[36] E. K. Onuma, and S. W. Hui, "Electric field-directed cell shape changes, displacement, and cytoskeletal reorganization are calcium dependent," The Journal of Cell Biology, 106(6), 2067-2075 (1988).

[37] G. Song, Y. Ju, X. Shen et al., "Mechanical stretch promotes proliferation of rat bone marrow mesenchymal stem cells," Colloids and Surfaces B: Biointerfaces, 58(2), 271-277 (2007). 